\title{
PEMBUATAN DAN KARAKTERISASI KOMPOSIT LiBOB/MgCI2 DENGAN METODE SOLID STATE REACTION
}

\author{
Arwin Darwis, Iswadi, dan Sahara ${ }^{1}$ \\ 1Jurusan Fisika, Fakultas Sains dan Teknologi, UIN Alauddin Makassar \\ Email: arwin.idea95@gmail.com, wadi.phys.uin@gmail.com, \\ rarafis_uin@yahoo.co.id
}

\begin{abstract}
The manufacture and characterization of the lithium bus Composite (oxalate) borate with the addition of magnesium chloride (LiBOB/MgCl2). Electrolytes as a media transfer ion battery, plays an important role in the charge-discharge process of lithium ion batteries. The basic ingredients used in the study are lithium hydroxide ( $\mathrm{LIOH})$, Borid acid (H3BO3), Our acid dehydrate ( $\mathrm{H} 2 \mathrm{C} 2 \mathrm{O} 4 \cdot 2 \mathrm{H} 2 \mathrm{O})$ and magnesium chloride hexahydrate $(\mathrm{MgCl} 2 \cdot 6 \mathrm{H} 2 \mathrm{O})$. The method used in this research is solid state reaction or known as solid-solid method. Based on the results of the XRD characterization, shows the peaks of LiBOB experiencing a shift after being added with $2.5 \%$; $5 \%$ and $7.5 \%$ $\mathrm{MgCl} 2 \cdot 6 \mathrm{H} 2 \mathrm{O}$, in addition it also raises new peaks of magnesium. While the spread of the material is blown the sample appears evenly with the SEM-EDX test, however there are some elements that are experiencing clotting. And the FTIR test showed a change in the frequency of each mass increase of $\mathrm{MgCl} 2 \cdot 6 \mathrm{H} 2 \mathrm{O}$, but did not cause peak changes in each sample. In the EIS test results, obtaining a low electrical conductivity value, due to agglomeration of the material after the addition of elemental magnesium that is ionic. Thus also causes the diffusion of ions to lower.
\end{abstract}

Keywords: $\mathrm{LiBOB} / \mathrm{MgCl}$, ion diffusion, characterization, solid state reaction

\section{PENDAHULUAN}

Lithium menjadi salah satu bahan baku pembuatan komponen penyimpan energi yaitu pada Baterai yang dikenal dengan istilah Lithium lon Batteries (LIBs). Baterai menjadi sumber energi yang murah dan praktis. Baterai terus mengalami pengembangan material baru sesuai dengan aturan efektifitas bahan. Baterai merupakan sel elektrokimia yang menghasilkan tegangan konstan sebagai hasil reaksi kimia. Pada umumnya, ada 2 jenis baterai yang dapat ditemukan dalam kehiduan sehari-hari, yaitu baterai primer yang hanya bisa dipakai sekali saja dan baterai sekunder yang bisa diisi ulang (Linden dan Reddy, 2004). Alasan utama baterai dimanfaatkan sebagai energi alternatif karena bentuknya sederhana, ringan, tahan lama dan energinya dapat diisi ulang (Park et al., 2010).

Baterai Lithium tersusun atas 4 komponen dasar, yaitu: Anoda, Katoda, Separator dan Elektrolit. Anoda merupakan elektroda negatif baik berupa logam 
maupun penghantar listrik lainnya yang mampu terpolarisasi jika arus listrik mengalir ke dalamnya. Katoda merupakan elektroda positif yang terpolarisasi jika arus mengalir keluar darinya. Sedangkan separator berfungsi sebagai pemisah antara elektroda negatif dan elektroda positif yang dapat mencegah terjadinya arus pendek (Arifin dan Zainuri, 2014). Sementara Elektrolit merupakan zat terlarut yang berfungsi sebagai media transfer ion dari anoda dan katoda serta berperan penting pada transmisi elektron pada saat pengisian dan pemakaian baterai.

Elektrolit harus mampu menghasilkan dan menghantarkan elektron untuk dapat menjalankan sel elektrokimia. Lithium bis (oxalate) borate (LiBOB) menjadi agregat yang menjanjikan sebagai garam elektrolit saat ini. LiBOB yang berbentuk Gel Polymer Electrolyte (GPE) memiliki beberapa keunggulan, yaitu mudah dalam mendesainnya dan memiliki kepadatan daya yang lebih tinggi (Azeez, 2009). Lithium bis (oxalate) borate (LiBOB) pertamakali dijelaskan oleh Lisckha, dkk pada tahun1990. Berdasarkan percobaan termogravimetri yang dilakukan oleh Lisckha (1999) menunjukkan bahwa LiBOB sepenuhnya stabil pada suhu sampai kira-kira $300^{\circ} \mathrm{C}$. Sementara penelitian Xu (2001), dengan mengkombinasikan Differsensial Analysis Thermal dengan Thermogravimetry Analysis (DTA-TGA) memperoleh tingkat kestabilan LiBOB sampai pada suhu $302^{\circ} \mathrm{C}$, melalui pemindaian dari $10^{\circ} \mathrm{C}$ $\min ^{-1}$. Penelitian lebih lanjut yang dilakukan Wigayati (2015) menyatakan bahwa LiBOB memiliki stabilitas termal yang terdekomposisi pada temperatur $303^{\circ} \mathrm{C}$, bersifat higroskopis, memiliki berat molekul $193.79 \mathrm{~g} / \mathrm{mol}$ dengan Densitas 0.8-1.2 $\mathrm{g} / \mathrm{cm}^{3}$, serta dapat larut pada campuran karbonat, carbolic ester, glymes, ketones dan lactones.

\section{METODE PENELITIAN}

Bahan utama yang gunakan pada penelitian ini yaitu: Lithium Hidroxide $(\mathrm{LiOH})$, Oxalic Acid $\left(\mathrm{H}_{2} \mathrm{C}_{2} \mathrm{O}_{4} \cdot 2 \mathrm{H}_{2} \mathrm{O}\right)$, Borid Acid $\left(\mathrm{H}_{3} \mathrm{BO}_{3}\right)$ dan Magnesium

Chloride Hexahydrate $\left(\mathrm{MgCl}_{2} \cdot 6 \mathrm{H}_{2} \mathrm{O}\right)$. Massa $\mathrm{MgCl}_{2} \cdot 6 \mathrm{H}_{2} \mathrm{O}$ ditentukan berturut- turut dari $0 \%, 2.5 \%, 5 \%$ dan $7.5 \%$ dari massa $\mathrm{LiOH}$ yang digunakan. Sementara itu, massa bahan lainnya yang digunakan mengikuti persamaan reaksi kimia berikut: $\mathrm{LiOH}+\mathrm{H}_{3} \mathrm{BO}_{3}+2 \mathrm{H}_{2} \mathrm{C}_{2} \mathrm{O}_{4} \cdot 2 \mathrm{H}_{2} \mathrm{O} \rightarrow \mathrm{LiB}\left(\mathrm{C}_{2} \mathrm{O}_{4}\right)_{2}+8 \mathrm{H}_{2} \mathrm{O} \quad$ Bahan-bahan tersebut digerus hingga homogen, kemudian di kalsinasi pada temperature $120^{\circ} \mathrm{C}$ dengan penahanan selama 4 jam, dilanjutkan dengan proses sintering pada temperature $250^{\circ} \mathrm{C}$ dengan penahanan selama 7 jam. Setelah itu, dilakukan uji karakterisasi LiBOB dengan menggunakan X-Ray Diffraction (XRD), Scanning Electron Microscope (SEM) dan Fourier Transform Infrared (FTIR).

\section{HASIL DAN PEMBAHASAN}

\section{Analisa X-Ray Diffraction (XRD)}

Proses identifikasi fasa yang diduga sebagai struktur LiBOB secara kualitatif dilakukan menggunakan software Highscore dengan pencocokan posisi- posisi 
puncak yang terukur dengan database dalam bentuk PDF. Pada gambar 4.1 dapat diamati bahwa hasil sintesis material aktif garam elektrolit $\mathrm{LiBOB} / \mathrm{MgCl}_{2}$ telah berhasil dilakukan. Keempat pola difraksi tersebut menunjukkan terbentuknya fasa LiBOB berdasarkan database [PDF 00-062-0917] dan LiBOB Hidrate berdasarkan database [PDF 01-073-9447].

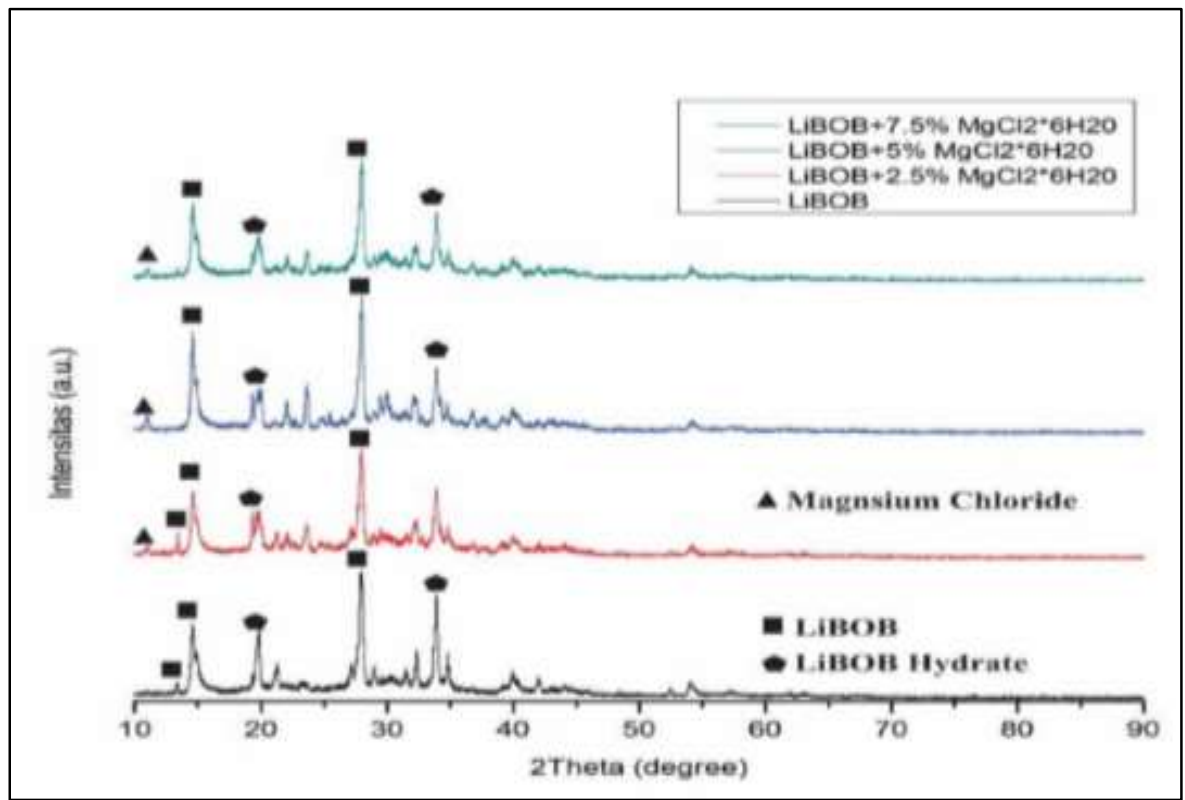

Grafik 1. Diagram fasa sampel hasil karakterisasi XRD

Keterangan dari grafik pola difraksi pada grafik 1 dijelaskan menggunakan tabel 1 tabel 4 pada saat 2 theta terhadap fasa yang terbentuk dan nilai bidang hkl pada lembaran elektrolit komposit.

Tabel 1. Data X-Ray Diffraction (XRD) untuk sampel komposit LiBOB dengan $0 \% \mathrm{MgCl}_{2}$

\begin{tabular}{cccccc}
\hline No & $\mathbf{2 0}$ & $\mathbf{d}(\check{\mathbf{A}})$ & Fasa & HKL & PDF Card No \\
\hline $\mathbf{1}$ & 13.367 & 6.619 & LiBOB & 011 & $00-062-0917$ \\
\hline $\mathbf{2}$ & 14.586 & 6.068 & LiBOB & 011 & $00-062-0917$ \\
\hline $\mathbf{3}$ & 19.859 & 4.467 & LiBOB Hydrate & 021 & $01-073-9447$ \\
\hline $\mathbf{4}$ & 27.959 & 3.278 & LiBOB & 022 & $00-062-0917$ \\
\hline $\mathbf{5}$ & 33.887 & 2.643 & LiBOB Hydrate & 250 & $01-073-9447$ \\
\hline
\end{tabular}


Tabel 2. Data X-Ray Diffraction untuk sampel komposit LiBOB dengan $2.5 \% \mathrm{MgCl}_{2}$

\begin{tabular}{cccccc}
\hline No & $\mathbf{2 0}$ & $\mathbf{d}(\mathbf{A})$ & Fasa & HKL & PDF Card No \\
\hline $\mathbf{1}$ & 11.04 & 8.01 & LiMgCl & 001 & $00-033-0823$ \\
\hline $\mathbf{2}$ & 13.456 & 6.575 & LiBOB & 001 & $00-062-0917$ \\
\hline $\mathbf{3}$ & 14.634 & 6.048 & LiBOB & 001 & $00-062-0917$ \\
\hline $\mathbf{4}$ & 19.834 & 4.473 & LiBOB Hydrate & 021 & $01-073-9447$ \\
\hline $\mathbf{5}$ & 27.958 & 3.188 & LiBOB & 022 & $00-062-0917$ \\
\hline $\mathbf{6}$ & 33.880 & 2.643 & LiBOB Hydrate & 250 & $01-073-9447$ \\
\hline
\end{tabular}

Tabel 3. Data X-Ray Diffraction untuk sampel komposit LiBOB dengan $5 \% \mathrm{MgCl}_{2}$

\begin{tabular}{cccccc}
\hline No & $\mathbf{2 0}$ & $\mathbf{d}(\mathbf{A})$ & Fasa & HKL & PDF Card No \\
\hline $\mathbf{1}$ & 11.04 & 8.027 & LiMgCl & 001 & $00-033-0823$ \\
\hline $\mathbf{2}$ & 13.456 & 6.045 & LiBOB & 011 & $00-062-0917$ \\
\hline $\mathbf{3}$ & 14.634 & 4.595 & LiBOB & 021 & $01-073-9447$ \\
\hline $\mathbf{4}$ & 19.834 & 4.479 & LiBOB Hydrate & 021 & $01-073-9447$ \\
\hline $\mathbf{5}$ & 27.958 & 3.182 & LiBOB & 022 & $00-062-0917$ \\
\hline $\mathbf{6}$ & 33.880 & 2.640 & LiBOB Hydrate & 250 & $01-073-9447$ \\
\hline
\end{tabular}

Tabel 4. Data X-Ray Diffraction untuk sampel komposit elektrolit PVdF-LiBOB dengan bahan aditif $\mathrm{MgCl} 27.5 \%$.

\begin{tabular}{cccccc} 
No & $\mathbf{2 \theta}$ & $\mathbf{d}(\mathbf{A})$ & Fasa & HKL & PDF Card No \\
\hline $\mathbf{1}$ & 11.07 & 8.027 & LiMgCl & 001 & $00-033-0823$ \\
\hline $\mathbf{2}$ & 14.610 & 6.045 & LiBOB & 011 & $00-062-0917$ \\
\hline $\mathbf{3}$ & 19.897 & 4.595 & LiBOB & 021 & $01-073-9447$ \\
\hline $\mathbf{4}$ & 27.982 & 4.479 & LiBOB Hydrate & 021 & $01-073-9447$ \\
\hline $\mathbf{5}$ & 33.927 & 3.182 & LiBOB & 022 & $00-062-0917$ \\
\hline
\end{tabular}

Dari grafik dan data elektrolit komposit di atas diketahui dengan penambahan massa $\mathrm{MgCl}_{2}$ akan terjadi perubahan intensitas puncak difraksi karena logam $\mathrm{MgCl} 2$ bersifat konduktif. Dari keempat sampel yang telah diuji menggunakan XRD, sampel pertama terlihat pada sudut 2 -theta $13.367^{\circ}$. Pada sampel B - sampel D terlihat pada sudut 2-theta $11.01^{\circ}-33.927^{0}$ intensitas puncak difraksi semakin meningkat karena penambahan $\mathrm{MgCl}_{2}$ serta munculnya fasa baru lithium magnesium chloride ( $\left.\mathrm{LiMgCl}\right)$ dengan intensitas yang tidak terlalu besar. Pada sampel $\mathrm{B}\left(2,5 \% \mathrm{MgCl}_{2}\right)$, terdeteksi fasa $\mathrm{MgCl}$ dengan ditemukannya nilai three strongest line $d=8.01 \AA$ yang cocok 
dengan standar database lithium magnesium chloride pada nomor PDF 00-0360690. Pada sampel C $\left(5 \% \mathrm{MgCl}_{2}\right)$, fasa $\mathrm{LiMgCl}$ terdeteksi dengan ditemukannya nilai three strongest line $d=8.027 \AA$. Pada sampel $D\left(7,5 \% \mathrm{MgCl}_{2}\right)$, fasa $\mathrm{LiMgCl}$ terdeteksi dengan ditemukannya nilai three strongest line $d=7.989 \AA$.

Dengan penambahan massa $\mathrm{MgCl}_{2}$ yang semakin besar, sehingga perubahan intensitas semakin besar dan menghasilkan fasa-fasa yang memiliki ukuran kristalit yang teridentifikasi seperti pada Tabel berikut;

Tabel 5. Fasa yang terbentuk dan ukuran kristalitnya pada sampel $\mathrm{D}$ $(\mathrm{MgCl} 27,5 \%)$.

\begin{tabular}{cccc} 
No & $\mathbf{2} \boldsymbol{\theta}$ & I (cps deg) & Ukuran Kristalit \\
\hline $\mathbf{1}$ & 11.07 & 82 & 73 \\
\hline $\mathbf{2}$ & 14.610 & 778 & 303 \\
\hline $\mathbf{3}$ & 19.897 & 346 & 552 \\
\hline $\mathbf{4}$ & 27.982 & 1011 & 541 \\
\hline $\mathbf{5}$ & 33.927 & 608 & 632 \\
\hline
\end{tabular}

Perubahan puncak (peak) pada sampel 2 - sampel 4 dikarenakan adanya penambahan $\mathrm{MgCl}_{2}$ yang meningkatkan intensitas sinar-x yang ditangkap oleh detektor XRD. Puncak-puncak yang terbentuk dari masing-masing sampel mengidentifikasi fasa-fasa yang terkandung pada sampel. Kaitan dari perubahan intensitas sinar- $x$ terjadi akibat penambahan $\mathrm{MgCl}_{2}$ yaitu semakin besar penambahan $\mathrm{MgCl}_{2}$ maka semakin besar intensitas sinar-x tersebut. Dan juga semakin kecil ukuran Kristal pada sampel menandakan tingkat ke kristalan material yang terkandung semakin tinggi dan rapat.

Hasil identifikasi menggunakan software Highscore juga terdeteksi fasa LiBOB dan LiBOB Hydrate dengan sistem kristal orthorhombic. Dari hasil identifikasi tersebut diperoleh nilai sudut kristalografi $\alpha=\beta=\gamma=90^{\circ}$. untuk fasa LiBOB memiliki space group 62: Pnma, sementara untuk fasa LiBOB Hydrate memiliki space group 61 : Pbca (Wigayati dan R. I. Purawiardi, 2015).

\section{Analisa Scanning Electron Microscope (SEM)}

Pengamatan morfologi dan distribusi partikel pada permukaan lembaran sampel dilakukan karakterisasi Scanning Electron Microscopy (SEM). Pengambilan gambar dilakukan dengan perbesaran 1000x - 10.000x perbesaran. Hasil karakterisasi morfologi komposit $\mathrm{LiBOB} / \mathrm{MgCl}_{2}$ sebagai berikut:

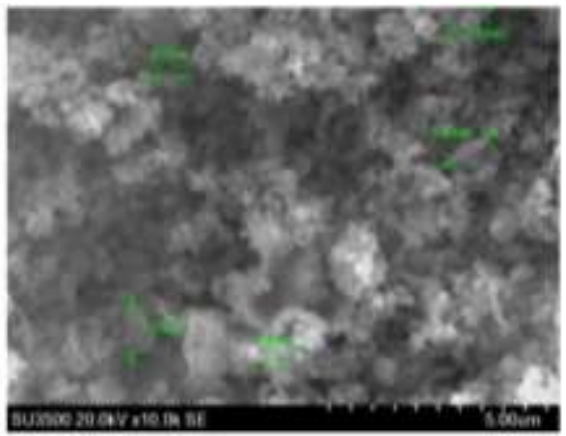

(a)



(b) 


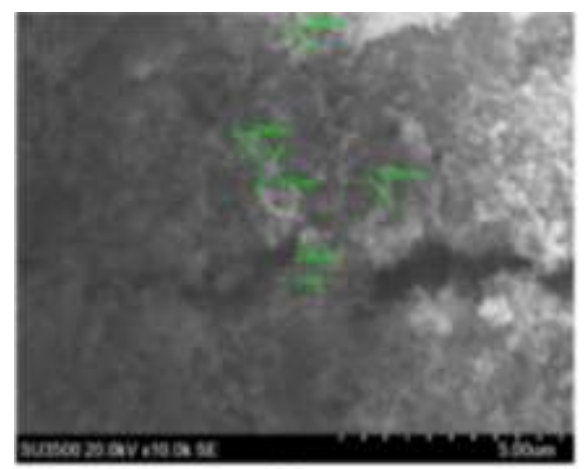

(c)

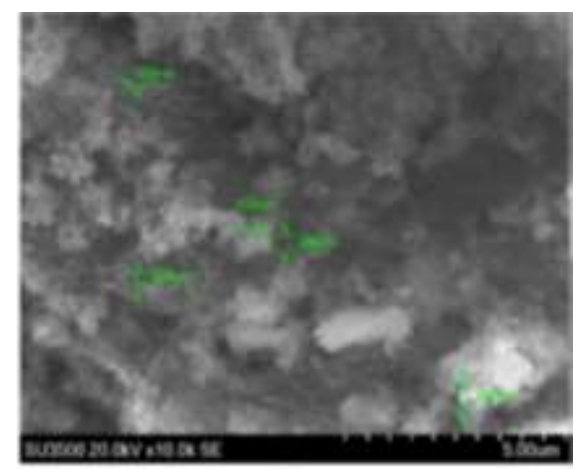

(d)

Gambar 1. Struktur morfologi LiBOB/MgCl2 degan perbesaran $10.000 x$, (a) $0 \%$ $\mathrm{MgCl}_{2}$, (b) 2,5\% $\mathrm{MgCl}_{2}$, (c) $5 \% \mathrm{MgCl}_{2}$ dan (d) $7,5 \% \quad \mathrm{MgCl}_{2}$, dilengkapi dengan panjang rata-rata ukuran partikel LiBOB.

Pada gambar 1 dengan perbesaran 10000 kali dapat diamati ukuran butir yang beraturan dan poros-poros yang dimiliki pada struktur LiBOB pada umumnya. Pada gambar 1(a) komposit LiBOB memiliki ukuran butir yang tidak homogen namun tetap tersebar merata. Sedangkan, pada gambar (b) sampai (d) untuk sampel LiBOB dengan variasi penambahan $\mathrm{MgCl}_{2}$ memiliki ukuran butir yang lebih kecil dibandingkan sampel A. Gambar diatas juga menunjukkan penampakan pori pada sampel $\mathrm{LiBOB} / \mathrm{MgCl}$. Sampel A terlihat banyak pori yang muncul dibandingkan sampel $B, C$ dan $D$ yang penyebaran partikelnya lebih rapat, sehingga pori yang muncul semakin kecil. Kerapatan pori tinggi maka menunjukkan jumlah pori yang terbentuk banyak dengan surface area yang luas (Arifin dan Zainuri, 2014).

Untuk mengetahui persebaran bahan pada setiap sampel, dilakukan pengujian SEM-EDX. Pengujian memberikan informasi mengenai banyak komposisi bahan tiap sampel yang ditinjau dari struktur permukaan atau morfologinya. 


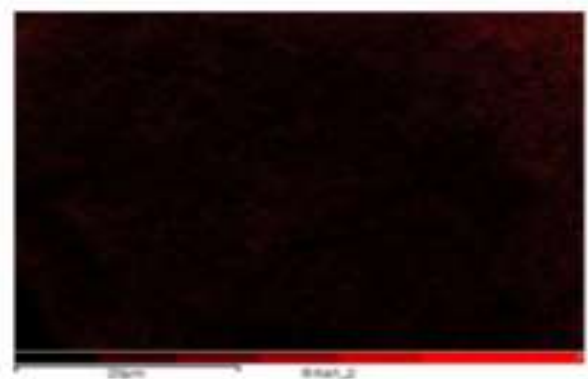

(a)

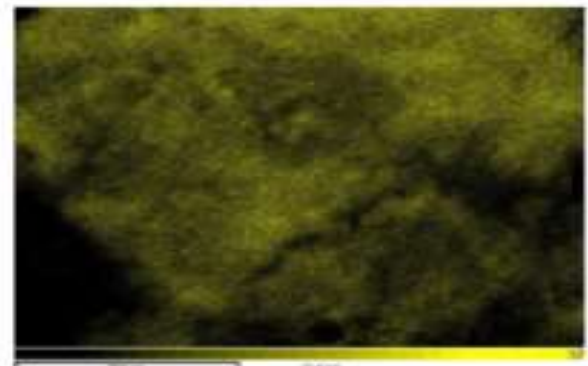

(c)

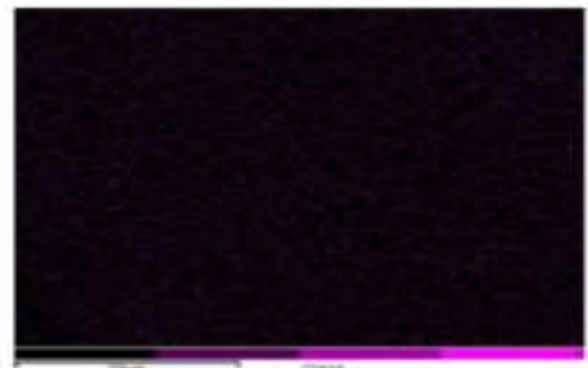

(e)

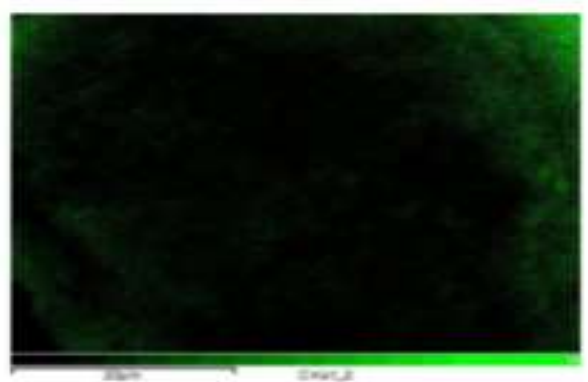

(b)

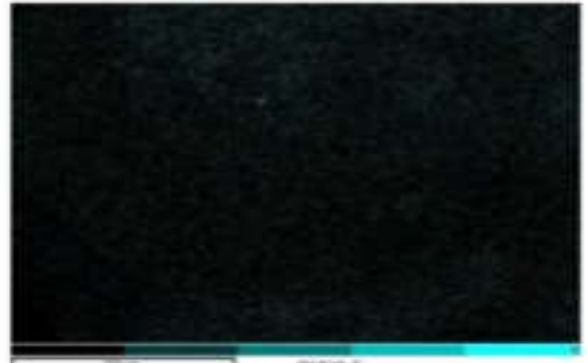

(d)



(f)

Gambar 2. Hasil analisa SEM-EDX sampel LiBOB dengan 2,5\% MgCl2 (a) persebaran Boron, (b) persebaran Carbon, (c) persebaran Oksigen, (d) persebaran

Magnesium, (e) persebaran Clorin dan (f) penampakan gabungan persebaran seluruh bahan.

Pada gambar 2 diatas, dapat dilihat persebaran Boron (B), Magnesium (Mg) dan Clorin $(\mathrm{Cl})$ tersebar merata pada penampakan permuakaan sampel. Sedangkan partikel Carbon (C) dan oksigen (O) terjadi penggumpalan pada beberapa titik tertentu. Hal ini juga terjadi pada sampel $\mathrm{C}$ dan $\mathrm{D}$ yang masing-masing dengan penambahan $5 \%$ dan $7,5 \% \mathrm{MgCl}_{2}$. Adanya aglomerasi pada sampel, dapat menyebabkan difusi ion yang dapat menurunkan kaspitas baterai ion lithium.

Jika dibandingkan dengan pengaruh penyebaran magnesium dan chlorin, terlihat bahwa $\mathrm{Mg}$ dan $\mathrm{Cl}$ mampu tersebar dengan baik secara merata dan berhasil untuk bercampur dengan unsur LiBOB pada umumnya. Dengan persebaran merata 
unsur magnesium ini menyebabkan difusi ion lithium pada $\mathrm{LiBOB} / \mathrm{MgCl} 2$ akan lebih cepat, sehingga mampu untuk meningkatkan kapasitas baterai lithium yang dihasilkan.

\section{Analisa Fourier Transform Infrared (FTIR)}

Perbandingan spectrum inframerah komposit $\mathrm{LiBOB} / \mathrm{MgCl} 2$ dapat dilihat pada gambar berikut.

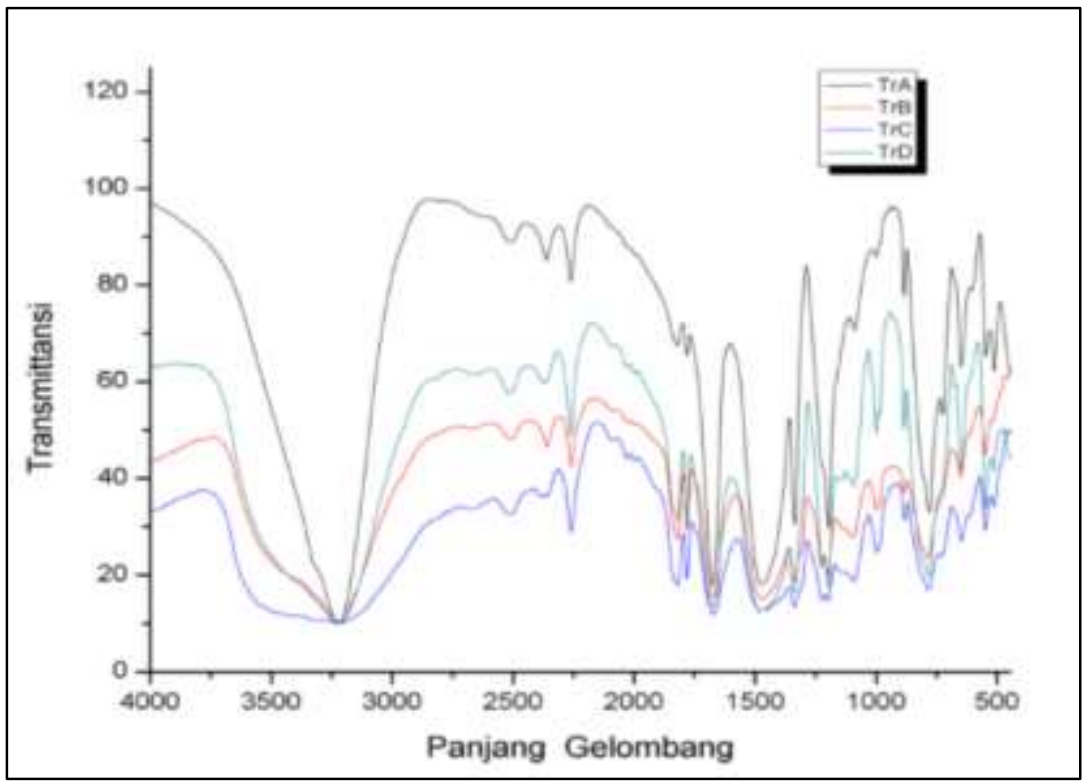

Gambar 3. Grafik hasil pengujian kualitatif spectrum inframerah

Spektrum infrared pada gambar diatas menunjukkan perbandingan dari LiBOB tanpa penambahan $\mathrm{MgCl}_{2}$ dan $\mathrm{LiBOB}$ dengan penambahan $\mathrm{MgCl}_{2}$. Ikatan gugus fungsi $\mathrm{LiBOB}$ dan $\mathrm{LiBOB} / \mathrm{MgCl}_{2}$ terdapat pada bilangan gelombang 1821 , $1781,1675,1337,1197,1093,783,650$ dan $511 \mathrm{~cm}^{-1}$. 
Tabel 6. Puncak spektrum gugus fungsi senyawa $\mathrm{LiBOB} / \mathrm{MgCl}_{2}$

\begin{tabular}{|c|c|c|c|c|}
\hline \multicolumn{4}{|c|}{ Bilangan Gelombang $\left(\mathrm{cm}^{-1}\right)$} & \multirow{2}{*}{ Gugus Fungsi } \\
\hline LiBOB-A & LiBOB-B & LiBOB-C & LiBOB-D & \\
\hline 3219.91 & 3217.04 & 3229.05 & 3218.71 & \multirow{4}{*}{$\mathrm{O}-\mathrm{H}$} \\
\hline 2514.28 & 2509.48 & 2520.13 & 2515.70 & \\
\hline 2361.09 & 2360.07 & 2259.60 & 2261.03 & \\
\hline 2261.46 & 2259.48 & & & \\
\hline 1819.96 & 1821.98 & 1821.14 & 1821.71 & $\mathrm{C}=\mathrm{O}$; osilasi fasa \\
\hline 1781.47 & 1781.34 & 1781.13 & 1781.73 & $\mathrm{C}=\mathrm{O}$; osilasi keluar fasa \\
\hline $\begin{array}{c}1675.28 \\
1473.92\end{array}$ & $\begin{array}{l}1673.77 \\
1471.22\end{array}$ & $\begin{array}{l}1671.58 \\
1479.96\end{array}$ & $\begin{array}{l}1674.32 ; \\
1472.39\end{array}$ & $\mathrm{C}-\mathrm{O}-\mathrm{O}$; regangan asimetris \\
\hline 1335.39 & 1336.91 & 1337.12 & 1337.03 & $\mathrm{C}-\mathrm{O}-\mathrm{B}-\mathrm{O}-\mathrm{C}$; regangan \\
\hline 1196.66 & 1196.93 & 1197.09 & 1196.69 & $\mathrm{C}-\mathrm{O}-\mathrm{C}$; regangan asimetris \\
\hline 884.09 & $\begin{array}{c}1093.19 \\
998.64\end{array}$ & $\begin{array}{c}1090.78: \\
997.98 ; \\
882.37\end{array}$ & $\begin{array}{c}1090.53 ; \\
998.41 ; \\
883.35\end{array}$ & $\begin{array}{l}\text { O-B-O; regangan asimetris dan } \\
\text { simetris }\end{array}$ \\
\hline 777.77 & 783.08 & 781.85 & 782.10 & $\mathrm{C}-\mathrm{O}-\mathrm{O}$; merusak bentuk \\
\hline $\begin{array}{l}648.35 \\
546.62\end{array}$ & $\begin{array}{c}650.86 \\
538.56\end{array}$ & $\begin{array}{l}648.15 \\
548.04\end{array}$ & 649.02 & B-O; merusak bentuk \\
\hline $\begin{array}{l}511.30 \\
447.65\end{array}$ & & & 446.85 & $\mathrm{BO}_{4}$; obligasi \\
\hline
\end{tabular}

Berdasarkan hasil identifikasi dengan menggunakan Tabel Hanawalt, puncakpuncak indek Miller dan menggabungkannya dnegan metode doctor blade technique menunjukkan adanya fasa LIBOB hidrat berdasar ICDD 01-073-9447 dan LIBOB berdasar ICDD00-056- 0139 yang tunggal maupun berimpit. Pada tabel diatas terlihat bahwa pengaruh penambahan $\mathrm{MgCl}_{2}$ secara umum meningkatkan jumlah fasa LIBOB maupun LIBOB hidrat yang terbentuk. Disamping itu juga mempengaruhi besarnya density maupun lattice parameter walaupun tidak terlalu signifikan. Hasil dari analisa XRD ini juga dikonfirmasi dengan analisa spektrum FTIR untuk mengetahui gugus fungsi pembentuk senyawa LIBOB.

\section{KESIMPULAN}

Diaftogram hasil analisa XRD menunjukkan terbentuknya fasa LiBOB dan LiBOB Hydrate. Sementara pada sampel B, C dan D menunjukkan munculnya fasa $\mathrm{LiMgCl}$ sebagai bahan impuritas yang ditambahkan pada LiBOB. Struktur Kristal yang terbentuk yaitu system kristal orthorhombik berdasarkan database PDF (00062-0917) dan PDF (01-073-9447).

Morfologi permukaan $\mathrm{LiBOB} / \mathrm{MgCl}_{2}$ memperlihatkan penyebaran yang merata bahan $\mathrm{Mg}$ dan $\mathrm{Cl}$. Sementara itu, ada penggumpalan didaerah tertentu pada bahan 
B, C dan O. Secara umum, dapat dilihat bentuk partikel LiBOB yaitu berbentuk panjang-bulat, dengan bentuk sedikit silinder.

Gugus Fungsi LiBOB terbentuk pada range antara $780^{\circ}-1800^{\circ}$. Pada hasil menunjukkan terjadinya fasa obligasi dan perusak bentuk LiBOB pada suhu tertentu. Selain itu, menunjukkan fasa munculnya Hydrogen. Namun, secara umum, tidak terlihat perubahan gugus fungsi dengan penambahan $\mathrm{MgCl}_{2}$.

\section{DAFTAR PUSTAKA}

Alfredsson, V. 2004. Mesoporous crystals and related nano-structured materials. Diedit oleh $O$. Terasaki. Amsterdam: Elsevier. Tersedia pada: http://www.fos.su.se/mcrm2004/Program_Workshop.doc. Berutu, Willy Von, Analisis Pengaruh Temperatur Hidrotermal terhadap Sifat Kapasitif Superkapasitor Berbahan Graphene. Surabaya, ITS. 2016.

Arifin, D. E. S. dan Zainuri, M. 2014. "Karakterisasi Sifat Separator Komposit PVDF/poli(dimetilsiloksan) Dengan Metode Pencampuran Membran (Blending Membrane)," Jurnal Sains dan Seni Pomits, 3(2), hal. 36-40. L.L. Zhang et al. dalam Diyan Unmu Dzujah, Charge-Discharge Model Superkapasitor rGO dalam Sistem Elektrolit KCl. Jurnal Ilmu dan Inovasi Fisika Vol. 02, No. 01. 2018.

Al-Mahali, Imam Jalaluddin dan Imam Jalaluddin As-Suyuti. 2000. Tafsir Jalalain. Bandung : Sinar Baru Algensindo Suheryanto, Dwi. Pembuatan Arang Bambu (Bamboo Charcoal) ada Suhu Rendah untuk Produk Kerajinan. Yogyakarta: Bali Besar Kerajinan dan Batik. 2013.

Brunschwig, B. S. et al. 2014. Fourier Transformation of an IR Interferogram. Instorumental Analysis Laboratory. Yulian, Annisa. Produksi Karbon Aktif dari Bambu Andong (Gigantochloa verticillata) Menggunakan Activating Agent $\mathrm{ZnCl}_{2}$ dan $\mathrm{CO}_{2}$. Depok: Universitas Indonesia.

Choi, N. et al. 2007. "Surface Layer Formed on Silicon Thin-Film Electrode in Lithium Bis(oxalato) Borate-Based Electrolyte," Journal of Power Sources, 172, hal. 404-409. doi: 10.1016/j.jpowsour.2007.07.058.

Choi, N. et al. 2007. "Surface Layer Formed on Silicon Thin-Film Electrode in Lithium Bis(oxalato) Borate-Based Electrolyte," Journal of Power Sources, 172, hal. 404-409. doi: 10.1016/j.jpowsour.2007.07.058.

Derrick, M. R., Stulik, D. dan Landry, J. M. 1999. Infrared Spectroscopy in Conservation Science: Scientific Tools for Conservation. Diedit oleh T. Ball. Los Angels: The Getty Conservation Institute.

Glusker, J. P. ., Lewis, M. dan Rossi, M. 1994. "Crystal Structure Analysis for Chemists and Biologists," VCH Publishers, hal. 837. doi: 10.1021/ed072pA73.9. 
Hong-ming, Z. et al. 2018. "Synthesis of Lithium Difluoro(oxalate)borate (LiODFB), Phase Diagram and Ions Coordination of LiODFB in Dimethyl Carbonate," Journal Cent. South Univ., 25, hal. 550-560.

Huggings, R. A. 2009. Advanced Batteries: Material Science Aspects. Stanford University: Springer.

Jullien, C. 2016. "Electrolytes and Separator for Lithium Batteries," in Lithium Batteries. Switzerland: Springer, hal. 431-460. doi: 10.1007/978-3-319-191089.

Lestariningsih, T., Marty Wigayati, E. dan Prihandoko, B. 2013. "Proses Pembentukan Senyawa LiB(C2O4)2 dengan Variasi Suhu Sintering," TELAAH Jurnal Ilmu Pengetauan dan Teknologi, 31(1), hal. 39-44.

Li, H. et al. 2011. "Gel polymer electrolytes based on active PVDF separator for lithium ion battery . I: Preparation and property of PVDF / poly (dimethylsiloxane) blending membrane," Journal of Membrane Science. Elsevier B.V., 379(1-2), hal. 397-402. doi: 10.1016/j.memsci.2011.06.008.

$\mathrm{Li}, \mathrm{X}$. et al. 2018. "Effects of Imide-Orthoborate Dual-Salt Mixtures in Organic Carbonate Electrolytes on the Stability of Lithium Metal Batteries," ACS Applied Materials \& Interfaces, 10, hal. 2469-2479. doi: 10.1021/acsami.7b15117.

Linden, D. dan Reddy, T. B. 2004. Handbook of batteries, McGraw-Hill. New York: McGraw-Hill. doi: 10.1016/0378-7753(86)80059-3.

Masaki, Y., Ralph J., B. dan Akiya, K. 2009. Lithium-Ion Batteries, Science and Technologies. Japan: Springer.

Michler, G. H. 2008. "Scanning Electron Microscopy (SEM)," in Electron Microscopy of Polymers. Berlin, Heidelberg: Springer Laboratory, hal. 87-120.

Mohr, S. H., Mudd, G. M. dan Giurco, D. 2012. "Lithium Resources and Production: Critical Assessment and Global Projections," Minerals, 2, hal. 65-84. doi: 10.3390/min2010065.

Nicolet, T. 2001. "Introduction to Fourier Transform Infrared Spectrometry," Thermo Nicolet. USA: Thermo Nicolet Corporation, hal. 1-8.

Park, M. et al. 2010. "A review of conduction phenomena in Li-ion batteries," Journal of Power Sources. Elsevier B.V., $x x x$, hal. 1-26. doi: 10.1016/j.jpowsour.2010.06.060. 
Priyono, S. et al. 2016. "Ketebalan Anoda Li4Ti5012 dan Studi Pengaruh Ketebalan Elektroda terhadap Performa Elektrokimia Baterai Ion Lithium," Jurnal Sains Materi Indonesia, 17(4), hal. 146-152.

Ramachandran, V. S. et al. 2002. Handbook of Thermal Analysis of Construction Material. New York: William Andrew Publishing.

Sakka, S. 2004. Handbook of Sol-Gel Science and Technology: Processing, Characterization and Applications. Diedit oleh H. Kozuka. Osaka: Kluwer Academic Publisher.

Sulistiyono, E. et al. 2018. "Study of Lithium Extraction from Brine Water, Bledug Kuwu, Indonesia by The Precipitation Series of Oxalic Acid and Carbonate Sodium," in Proceedings of the International Seminar on Metallurgy and Materials (ISMM2017), hal. 020007-1-020007-6. doi: 10.1063/1.5038289.

Sumarno, Ratnawati dan Nugroho, A. 2012. "Recovery Garam Lithium dari Air Asin (Brine) dengan Metoda Presipitasi," Teknik, 33(2), hal. 66-70.

Suryanarayana, C. dan Norton, M. G. 1998. X-Ray Diffraction: A Practical Approach. New York: Springer Science+Business Media, LLC.

Wigayati, E. M. et al. 2017. "Synthesis of LiBOB Fine Powder to Increase Solubility," Makara Journal Technology, 21(1), hal. 26-32. doi: 10.7454/mst.v21i1.3076.

Wigayati, E. M. dan Purawiardi, I. 2015. "Sintesis LiBOB dan Analisa Struktur Kristalnya," Majalah Metalurgi, V, hal. 81-88.

Wigayati, E. M., Purawiardi, I. dan Sabrina, Q. 2017. "Karakterisasi Morfologi Permukaan pada Polimer PVdf-LiBOB-ZrO2 dan Potensinya untuk Elektrolit Baterai Lithium," Jurnal Kimia dan Kemasan, 39(2), hal. 47-54. doi: 10.24817/jkk.v39i2.3306.

Wigayati, E. M. dan Purawiardi, R. I. 2015. "Analisis Pengaruh Mechanical Milling menggunakan Planetary Ball Milling terhadap Struktur Kristal dan Struktur Mikro Senyawa LiBOB," Jurnal Sains Materi Indonesia, 16(3), hal. 126- 132. Tersedia pada: http://jusami.batan.go.id.

Zhang, Y. et al. 2012. "Advances in new cathode material LiFePO 4 for lithium- ion batteries," Synthetic Metals. Elsevier B.V., 162(13-14), hal. 1315-1326. doi: 10.1016/j.synthmet.2012.04.025.

Zhou, W. et al. 2005. "Fundamentals of Scanning Electron Microscopy," in Scanning Electron Microscopy, hal. 1-40. 